\title{
THE SELIMIYE MOSQUE OF EDIRNE, TURKEY - AN IMMERSIVE AND INTERACTIVE VIRTUAL REALITY EXPERIENCE USING HTC VIVE
}

\author{
T. P. Kersten ${ }^{\text {a }}$, G. Büyüksalih ${ }^{\text {b }}$, F. Tschirschwitz ${ }^{\text {a }}$, T. Kan ${ }^{\text {b }}$, S. Deggim ${ }^{\text {a }}$, Y. Kaya ${ }^{\text {b }}$, A. P. Baskaraca ${ }^{\text {b }}$ \\ a 1HafenCity University Hamburg, Photogrammetry \& Laser Scanning Lab, Überseeallee 16, D-20457 Hamburg, Germany - \\ (Thomas.Kersten, Felix.Tschirschwitz, Simon.Deggim)@hcu-hamburg.de \\ b Boğaziçi İnşaat Müşavirlik A.Ş., Evliya Celebi Mah. Mesrutiyet Cad. Eski TÜYAP Binasi No. 50 Beyoglu, Istanbul, Turkey - \\ (gurcan.buyuksalih, tuna.kan, yusra.kaya, apeyami.baskaraca)@bimtas.istanbul
}

\section{Commission IV}

KEY WORDS: 3D, HTC Vive, modelling, reconstruction, virtual reality

\begin{abstract}
:
Recent advances in contemporary Virtual Reality (VR) technologies are going to have a significant impact on veryday life. Through VR it is possible to virtually explore a computer-generated environment as a different reality, and to immerse oneself into the past or in a virtual museum without leaving the current real-life situation. For such the ultimate VR experience, the user should only see the virtual world. Currently, the user must wear a VR headset which fits around the head and over the eyes to visually separate themselves from the physical world. Via the headset images are fed to the eyes through two small lenses. Cultural heritage monuments are ideally suited both for thorough multi-dimensional geometric documentation and for realistic interactive visualisation in immersive VR applications. Additionally, the game industry offers tools for interactive visualisation of objects to motivate users to virtually visit objects and places. In this paper the generation of a virtual 3D model of the Selimiye mosque in the city of Edirne, Turkey and its processing for data integration into the game engine Unity is presented. The project has been carried out as a co-operation between BİMTAŞ, a company of the Greater Municipality of Istanbul, Turkey and the Photogrammetry \& Laser Scanning Lab of the HafenCity University Hamburg, Germany to demonstrate an immersive and interactive visualisation using the new VR system HTC Vive. The workflow from data acquisition to VR visualisation, including the necessary programming for navigation, is described. Furthermore, the possible use (including simultaneous multiple users environments) of such a VR visualisation for a $\mathrm{CH}$ monument is discussed in this contribution.
\end{abstract}

\section{INTRODUCTION}

Virtual Reality (VR) will change our future life. Although VR is not very new, it is currently at the beginning of a technological transition. The term Virtual Reality was introduced the first time by the author Damien Broderick in his science fiction novel "The Judas Mandala" published in 1982. As early as 1962, Morton Heilig built the Sensorama, a machine that is one of the earliest known examples of immersive, multisensory (now known as multimodal) technology and which could be named as the first VR system (Rheingold 1991). Nevertheless, it took another thirty years until the first HeadMounted Display (HMD) for the mass market was released with the VFX 1 from Forte (Cochrane 1994). Unfortunately, this headset caused nausea and disturbances of equilibrium for users due to the long latency when visually updating the display. After almost another twenty years the new HMD Oculus Rift was announced by Palmer Luckey, which really worked and which rang in the new era (Desai et al. 2014).

It is already obvious that this new technology will offer great opportunities for many applications such as medicine, engineering, computer sciences, architecture, cultural heritage and virtual restoration. VR typically refers to computer technologies that use software to generate the realistic images, sounds and interactions that replicate a real environment, and simulate a user's physical presence in this environment. Furthermore, VR has been defined as a realistic and immersive

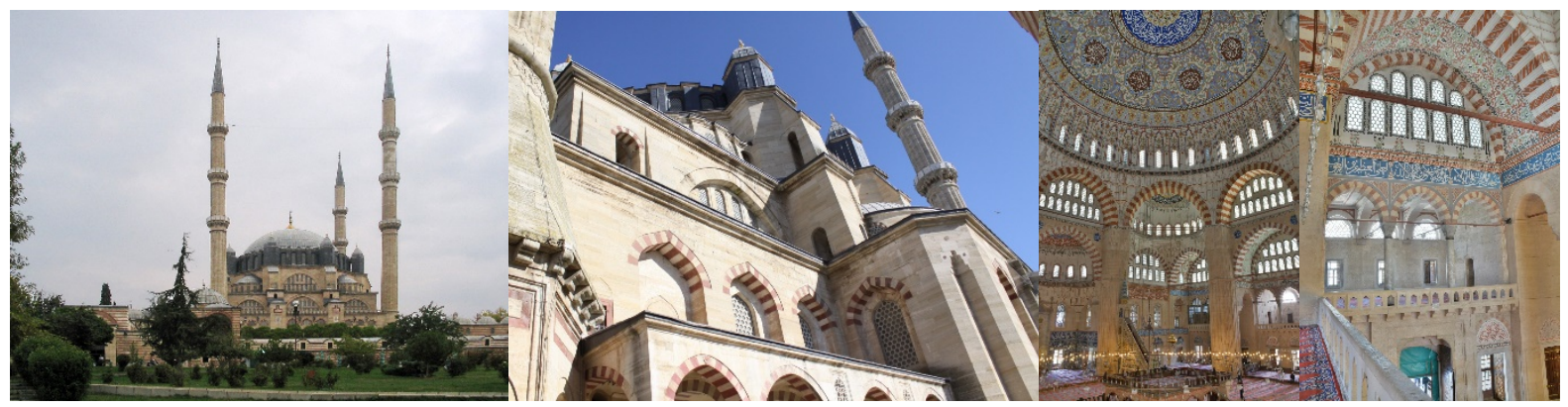

Figure 1. The mosque of Edirne, Turkey - exterior view (left), detail view (centre) and interior view (right)

* Corresponding author 
simulation of a three-dimensional environment, created using interactive software and hardware, and experienced or controlled by movement of the user's body or as an immersive, interactive experience generated by a computer. VR offers an attractive opportunity to visit objects in the past (Gaitatzes et al. 2001) or places, which are not easily accessible, often from positions which are not possible in real life. Moreover, these fundamental options are increasingly being implemented today through so-called "serious games", which embed information in a virtual world and create an entertaining experience (edutainment) through the flow of and interaction with the game (Anderson et al. 2010; Mortara et al. 2014). The first virtual museum using the VR system HTC Vive as a HMD for immersive experiences was introduced by Kersten et al. (2017).

BİMTAŞ, a company of the Greater Municipality of Istanbul, Turkey, generated a virtual 3D model of the mosque of Selimiye for the Edirne City Government to promote the monument for tourism purposes. This 3D model has also been processed in co-operation with the Photogrammetry \& Laser Scanning Lab of the HafenCity University Hamburg, Germany, for VR application to become the first historical monument in Turkey that is visualised as an immersive and interactive experience using the new VR system HTC Vive.

\section{THE SELIMIYE MOSQUE IN EDIRNE, TURKEY}

The Selimiye Mosque (Fig. 1) is an Ottoman imperial mosque, which is located in the city of Edirne, Turkey. The four pencilshaped minarets, which are the tallest ever built $(71 \mathrm{~m}$ from the ground to top), give the mosque an unforgettable profile. A detailed description about the mosque is given by Blair \& Bloom (1995). The mosque was commissioned by Sultan Selim II, and was built by the architect Mimar Sinan between 1569 and 1574 as a masterpiece and as one of the highest achievements of Islamic architecture. This grand mosque stands at the centre of a külliye (complex of a hospital, school, library and/or baths around a mosque) that comprises a medrese (Islamic academy teaches both Islamic and scientific lessons), a dar-ül hadis (Al-Hadith school), a timekeeper's room and an arasta (row of shops). In this mosque Sinan employed an octagonal supporting system that is created through eight pillars incised in a square shell of walls. The four semi domes at the corners of the square behind the arches that spring from the pillars, are intermediary sections between the huge encompassing dome (31.25 $\mathrm{m}$ diameter with spherical profile) and the walls.

Surrounded by the four tall minarets, the Mosque of Selim II has a grand dome atop it. Around the rest of the mosque were many additions: libraries, schools, hospices, baths, soup kitchens for the poor, markets, hospitals, and a cemetery. These annexes were axially aligned and grouped if possible. In front of the mosque sits a rectangular court with an area equal to that of the mosque. The innovation however, comes not in the size of the building, but from the organization of its interior. The mihrab is pushed back into an apse-like alcove with a space with enough depth to allow for window illumination from three sides. This has the effect of making the tile panels of its lower walls sparkle with natural light. The amalgamation of the main hall forms a fused octagon with the dome-covered square. Formed by eight massive dome supports, the octagon is pierced by four half dome covered corners of the square. The beauty resulting from the conformity of geometric shapes engulfed in each other was the culmination of Sinan's lifelong search for a unified interior space. The mosque, together with its külliye, was included on UNESCO's World Heritage List in 2011.

\section{WORKFLOW}

The following workflow has been carried out to generate a virtual 3D model of the Edirne mosque: (1) data acquisition using terrestrial laser scanning with the Riegl VZ-400 scanner, (2) 3D modelling using point clouds for generating 3D meshes with Autodesk ReCap or Geomagic studio and for solid modelling with $3 \mathrm{ds}$ Max, (3) texture mapping of polygon models, (4) generation of videos of the textured 3D model, (5) data reduction (polygon decimation) for VR application, (6) data conversion for the import into the game engine Unity, (7) implementation into the HTC Vive including the programming for the motion control, and (8) immersive and interactive visualisation of the mosque in the VR system HTC Vive.

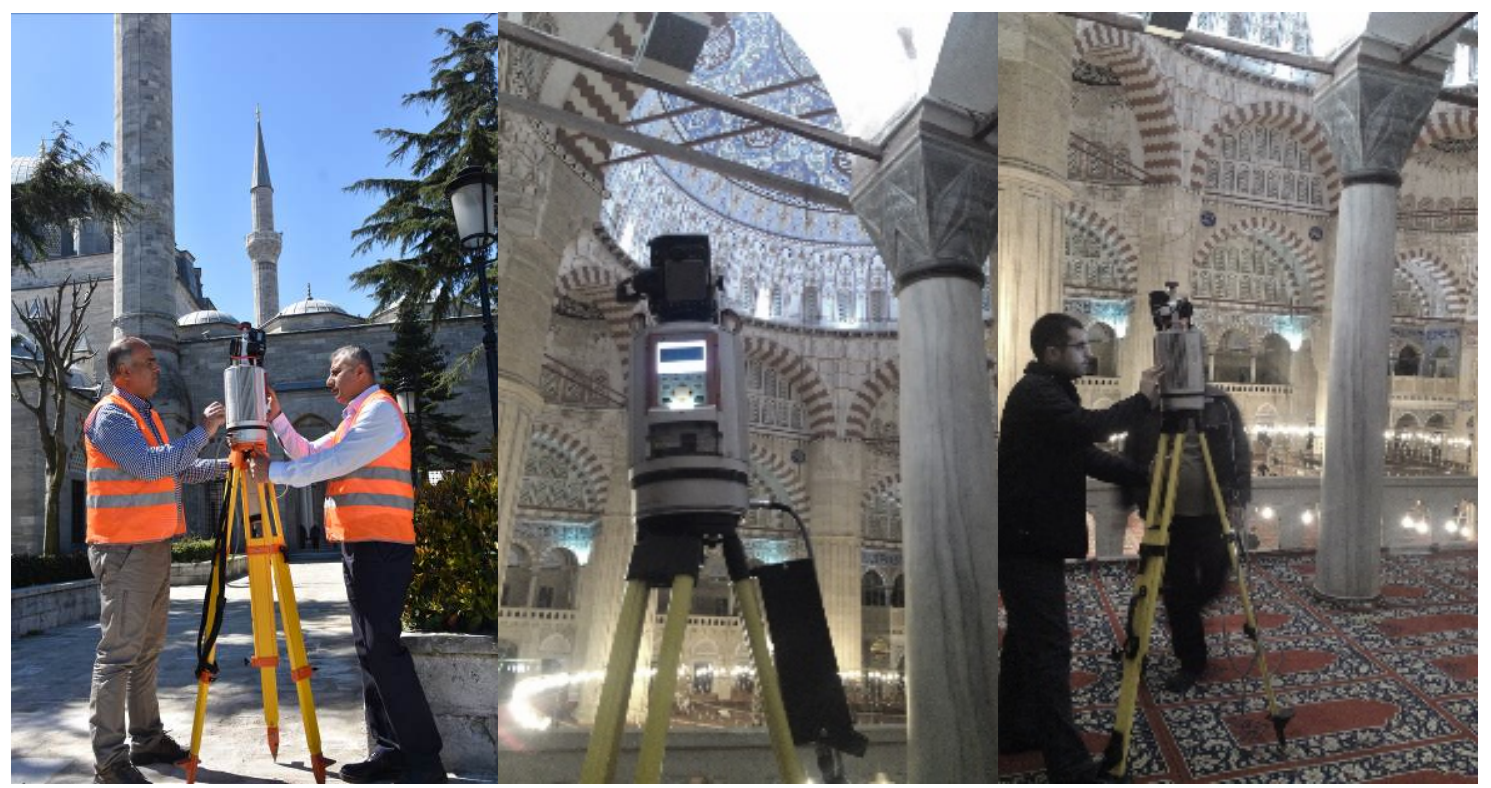

Figure 2. Data acquisition with the terrestrial laser scanning system Riegl VZ-400 on top of a minaret (left) and inside the mosque (centre and right) 


\section{DATA ACQUISITION AND 3D MODELLING}

The scanning of the mosque and its environment took almost one month (some days in September and November 2012) using one terrestrial laser scanning system Riegl VZ-400 and three staff members of BİMTAŞ (Fig. 2). In total, 110 interior scans and 447 exterior scans of the mosque were acquired with an average scan density of six points per $\mathrm{cm}^{2}$. Reflective targets were only used at some scan stations for geo-referencing of the point cloud. For later colorizing of the laser scanning point clouds (Fig. 3) an integrated Nikon D700 camera with $20 \mathrm{~mm}$ lens was placed on top of the Riegl scanner. Five images per $360^{\circ}$ view per scan were acquired. All scans were registered in the Riegl RiScanPro software with a precision of approximately 2-3 $\mathrm{mm}$. In total a data volume of 3.5 billion laser points were scanned. Processing in RiScanPro took approximately eighteen person weeks. To geo-reference the laser scanning point clouds for the interior and exterior areas of the mosque and to integrate the data into the national coordinate system a 3D geodetic network, including the reflective targets, was measured prior to scanning using total stations and GNSS.

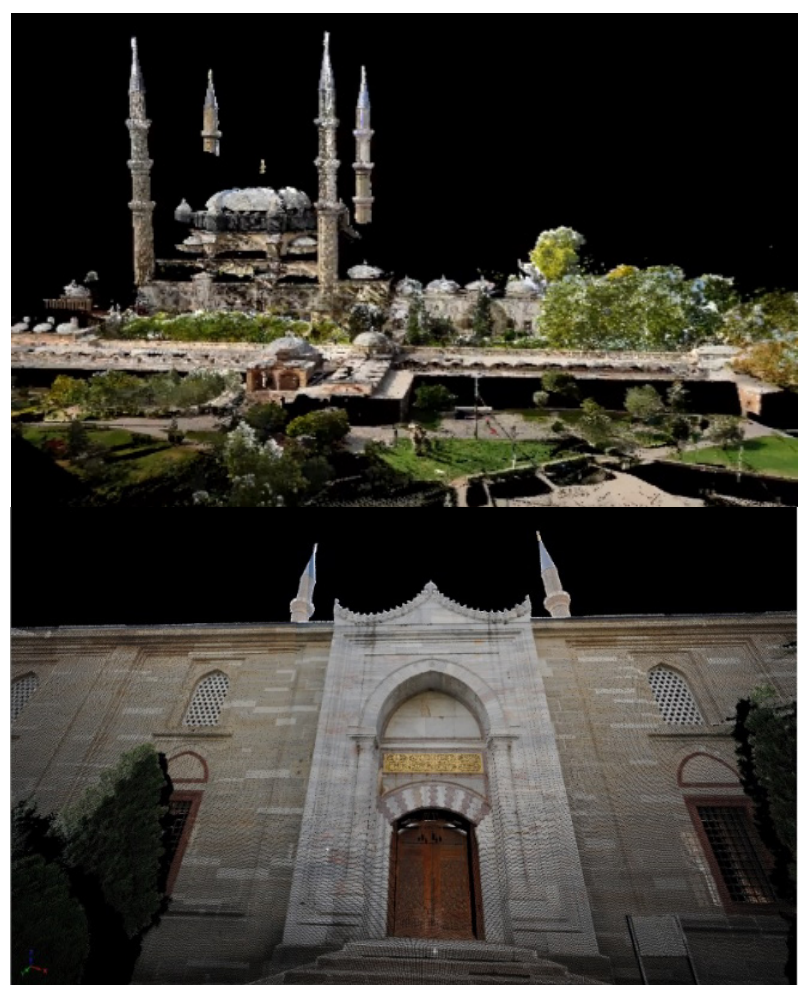

Figure 3. Part of the coloured point cloud of the Edirne mosque - overview (top) and detail (bottom)

The 3D modelling of the mosque took 24 person weeks to perform. In this step, geo-referenced point clouds were imported to Autodesk Recap and Geomagic studio (for smaller details) for the generation of 3D meshes (Fig. 4). These meshes were used as the basis for solid modelling in the program $3 \mathrm{ds}$ Max to derive CAD drawings and the 3D model. Similar workflows were presented by Dursun et al. (2008) and Kersten et al. (2009).

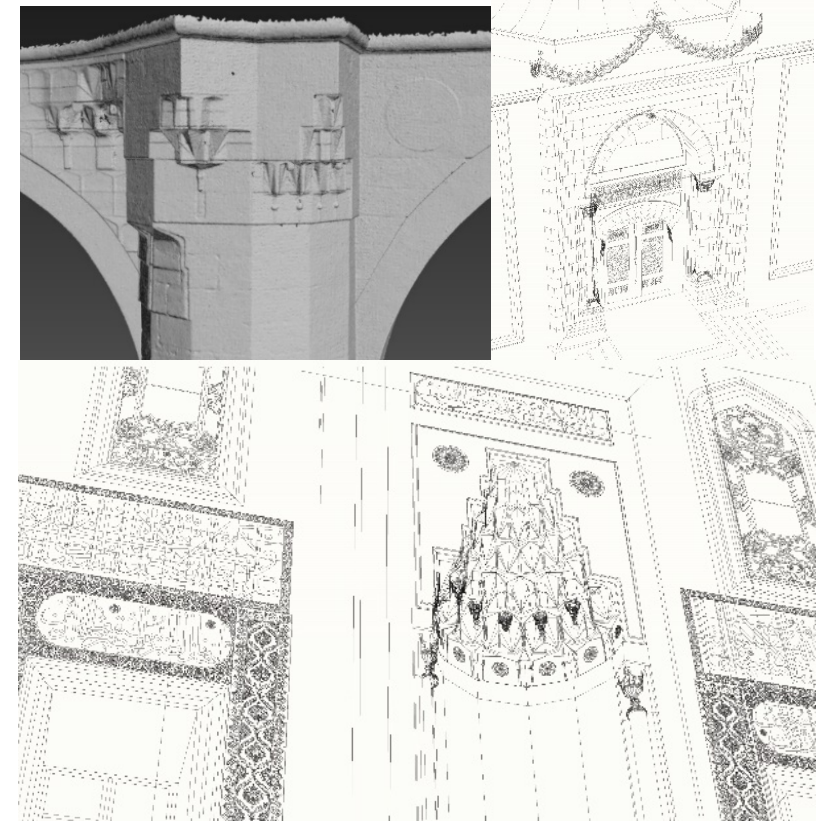

Figure 4. Mesh used for solid modelling in 3ds Max (top left) and 3D CAD drawing of the front door (top right) and section

of the interior area (bottom) of Edirne Selimiye mosque

For later texture mapping of the solid 3D model of the mosque (Fig. 5) photographs were taken using the Nikon D90 cameras during the field campaign. These images were radiometrically enhanced in Photoshop before texture mapping.

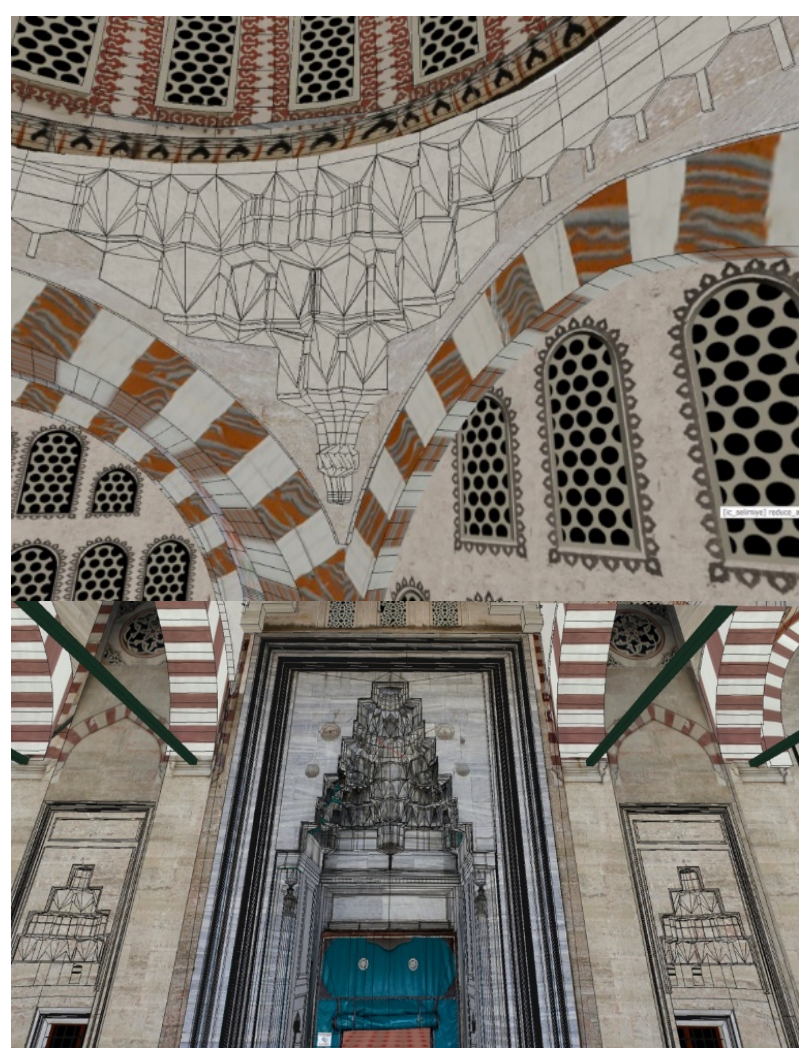

Figure 5. Textured 3D model superimposed with the wireframe view 


\section{GENERATION OF A VIDEO SEQUENCE}

To generate a video sequence for tourist applications the solid 3D model of the mosque (Fig 5) was exported as FBX file format for use in the visualisation software Lumion from Act3D B.V. in Warmond, The Netherlands. Lumion enables users to create videos and images without any prior training by editing the generated environment in real-time and by extremely fast rendering using GPU rendering technology. All atmospheric and light effects were prepared in this software before rendering. The complete rendering took two days using four computers with GTX 970 graphics card, 16 GB RAM and Intel i7 4700K processor. Finally, video sequences of different lengths (e.g. between 5 and 15 minutes) were produced in the format MPEG4, which were merged to one video file with a final length of 16:51 minutes and a data volume of 1.3 GByte (Fig. 6). This video also includes a two-minute sequence of a visualisation, which was generated with RiScanPro, of the coloured 3D point clouds of the mosque.

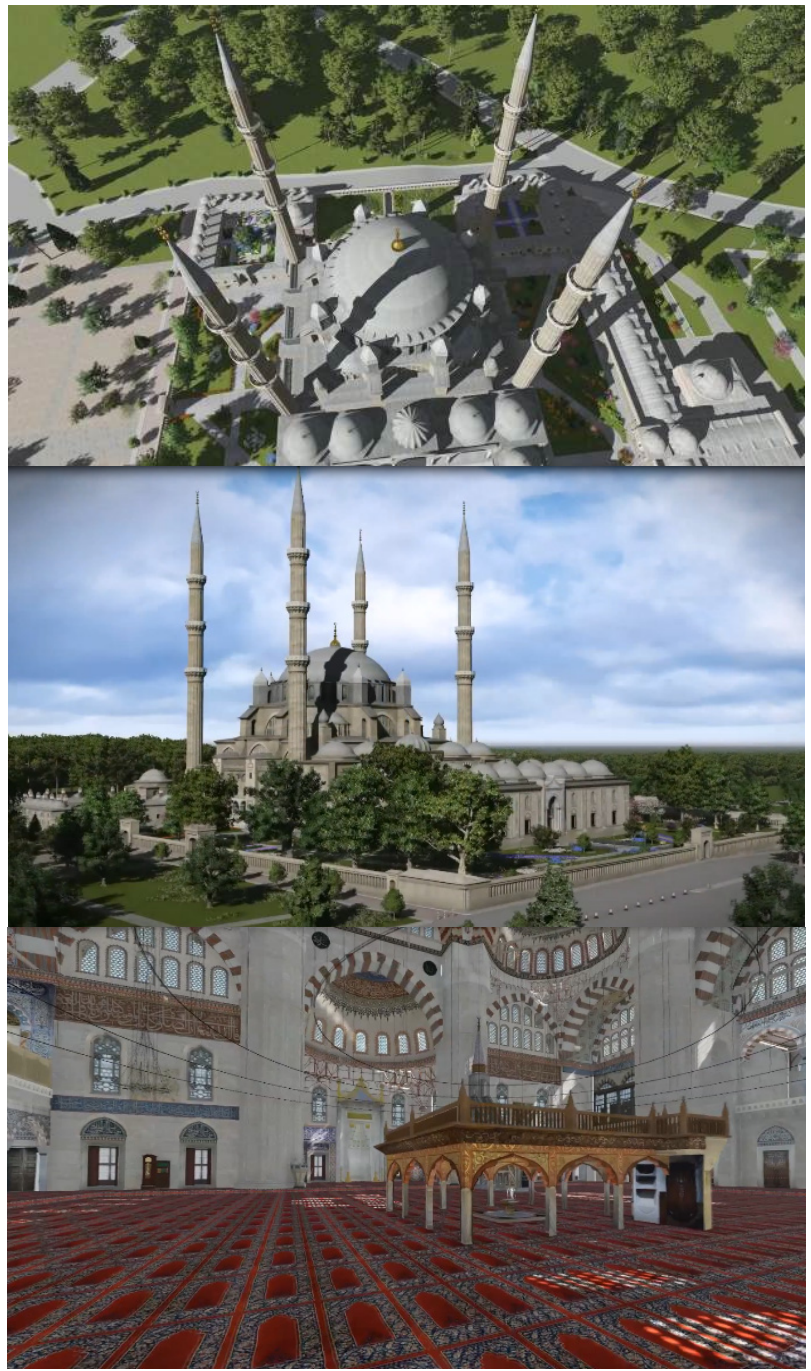

Figure 6. Still video frames of the video sequence of the Selimiye mosque of Edirne - perspective views of the exterior (top and centre) and interior (bottom)

\section{THE GAME ENGINE UNITY}

For the virtual reality application the game engine Unity was used. A game engine is a software framework designed for the creation and development of video games for consoles, mobile devices and personal computers. The core functionality typically provided by a game engine includes a rendering engine for $2 \mathrm{D}$ or $3 \mathrm{D}$ graphics to display textured 3D models (spatial data), a physics engine or collision detection (and collision response) for the interaction of objects, an audio system to emit sound, scripting, animation, artificial intelligence, networking, streaming, memory management, threading, localisation support, scene graph, and may include video support for cinematics. A game engine offers the ability to control the course of the game and is responsible for the visual appearance of the game rules. For the development of a virtual reality application, game engines offer many necessary concepts with much functionality so that users can interact with the virtual object. The solid 3D model of the mosque was transferred to Unity using FBX file format. However, the data volume of the model had to be reduced from 6 million polygons to fewer than two million polygons to guarantee sufficient computer performance during VR visualisation. At the end of processing in Unity, an executable program for the VR system HTC Vive was developed.

\section{THE VR SYSTEM HTC VIVE}

HTC Vive (www.vive.com) is a virtual reality headset (Fig. 7) for room-scale virtual reality. It was developed by HTC and Valve Corporation, was released on 5 April 2016, and is currently available on the market for EUR 899. Basic components are the headset for the immersive experience, two controllers for user interactions and two "Lighthouse" base stations for tracking the user's movement (Fig. 8). The visit offers the possibility of experiencing the mosque from a real person point of view and interaction scheme. For this purpose, the controlling positions have been defined by the possibility of free movement by the user. To bridge long distances in the virtual object, teleportation or fly-through functions can be developed for navigation of the user.

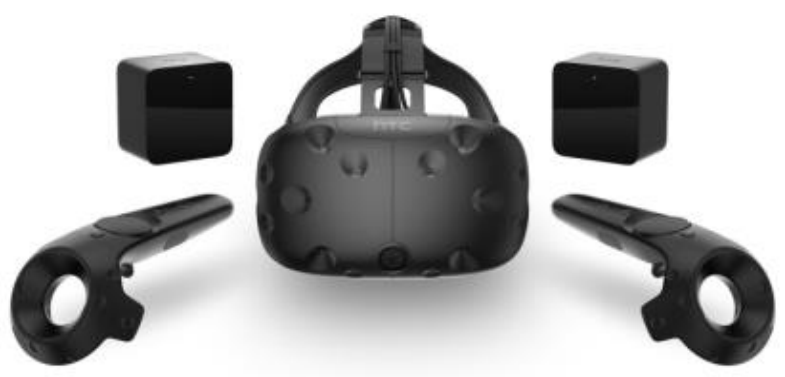

Fig. 7. The components of the Virtual Reality System HTC Vive 


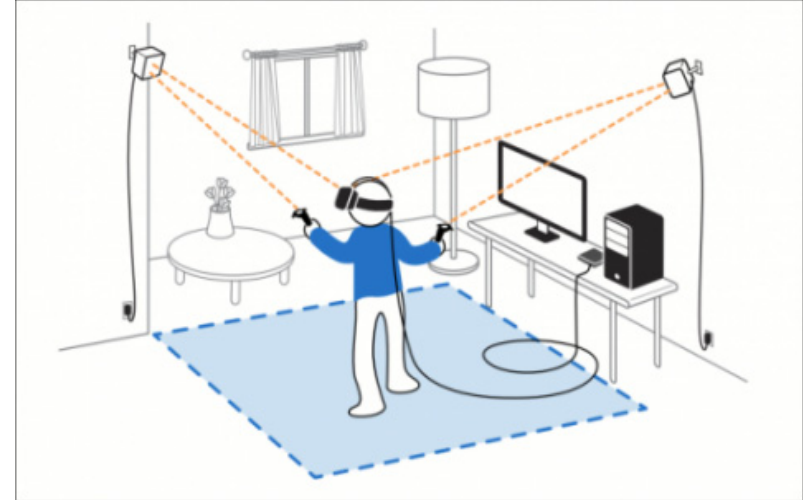

Fig. 8. The setup of the Virtual Reality System HTC Vive

The technical specifications of the HTC Vive are summarized in the following: a) two screens with a field of view of approximately 110 degrees, one per eye, each having a display resolution of $1080 \times 1200$ with a refresh rate of $90 \mathrm{~Hz}, \mathrm{~b})$ more than 70 sensors including a MEMS (Microelectromechanical systems) gyroscope, accelerometer and laser position sensors, c) 4.6 by $4.6 \mathrm{~m}$ tracking space for user operation using two "Lighthouse" base stations for tracking the user's movement with sub-millimetre precision by emitting pulsed IR lasers, d) SteamVR running on Microsoft Windows as the platform/operating system, e) controller input by SteamVR tracked wireless motion controllers, and f) front-facing camera for looking around in the real world to identify any moving or static object in a room as part of a safety system.

The following details the minimum required computer specification (HTC Corporation 2017): processor Intel ${ }^{\mathrm{TM}}$ Core $^{\mathrm{TM}}$ i5-4590 or AMD FX ${ }^{\mathrm{TM}}$ 8350, graphic card NVIDIA GeForce $^{\mathrm{TM}}$ GTX 1060 or AMD Radeon ${ }^{\mathrm{TM}}$ RX 480, 4 GB RAM, video output 1x HDMI 1.4-connection or DisplayPort 1.2 or newer, 1x USB 2.0-connection or newer, operating system Windows $^{\mathrm{TM}} 7 \mathrm{SP} 1$, Windows ${ }^{\mathrm{TM}} 8.1$ or more up to date or Windows ${ }^{\mathrm{TM}} 10$.

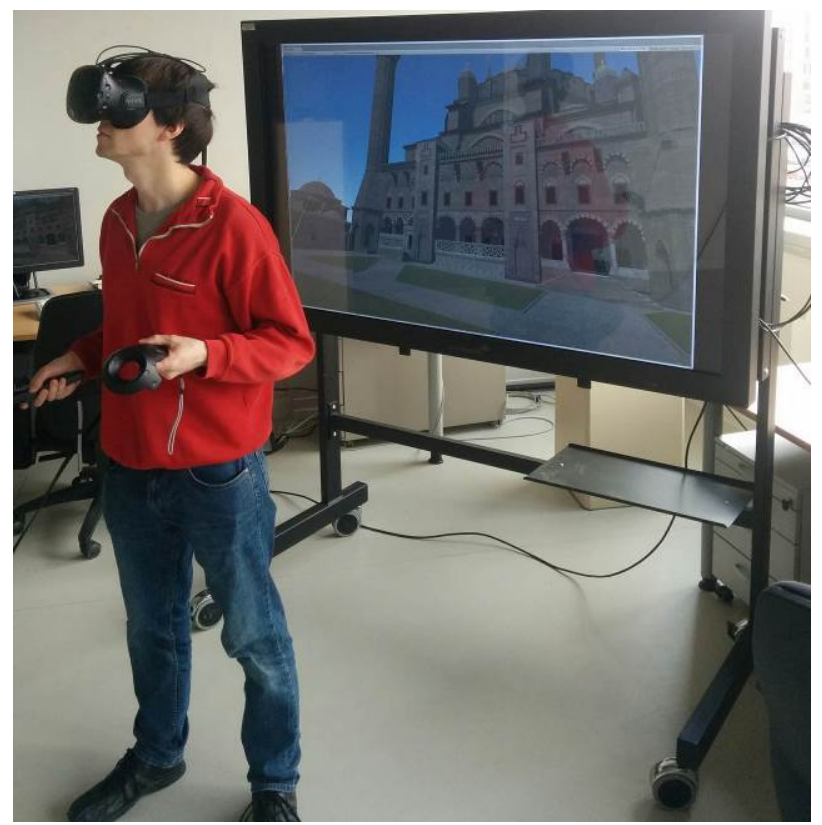

Fig. 9. The Virtual Reality System HTC Vive in action using the controllers for interacting in the environment
The device uses a gyroscope, accelerometer, and laser position sensor to track the head's movements as precisely as one-tenth of a degree. Wireless controllers in each hand, with precise SteamVR-tracking, enable the user to freely explore virtual objects, people and environments, and to interact with them. The VIVE-controller is specifically designed for VR with intuitive control and realistic haptic feedback. The Lighthouse system uses simple photo sensors on any object that needs to be captured. To avoid occlusion problems and increase tracking accuracy, this is carried out with two lighthouse stations that sweep structured light lasers within the space. Fig. 9 shows the VR system HTC Vive in action illustrating the view in the HMD on a TV screen.

\section{DATA REDUCTION FOR VR APPLICATION}

The final CAD model of the Selimiye mosque comprised 6.5 million polygons. This amount of data was too large for an acceptable performance of the VR application in the game engine Unity. Thus, the number of polygons had to be significantly reduced to ensure smooth performance during the motion in and interaction with the virtual 3D model using the VR system HTC Vive. In the first step, the number of polygons was reduced from 6.500.000 to 1.508.135. However, this polygon reduction caused a number of problems in the solid 3D model, which were visible during the visual inspection of the virtual model in the VR system HTC Vive. The problems that occurred are summarized in the following: (a) gaps, texture and UVW shifts on the objects, (b) double faces on the objects, (c) missing elements which are available in the original data structure of the mosque, and (d) errors with proportionality of objects in comparison with the original structure of the mosque. However, these above-listed problems and errors were corrected by additional manual modelling and reconstruction. Furthermore, all dense polygon objects were replaced by low polygon objects for further data reduction. Finally, the number of polygons was reduced to 901.133 . The mosque objects with reduced polygons are indicated in colour in Fig. 10. Fig 11 illustrates two examples of polygon reduction using two different objects.

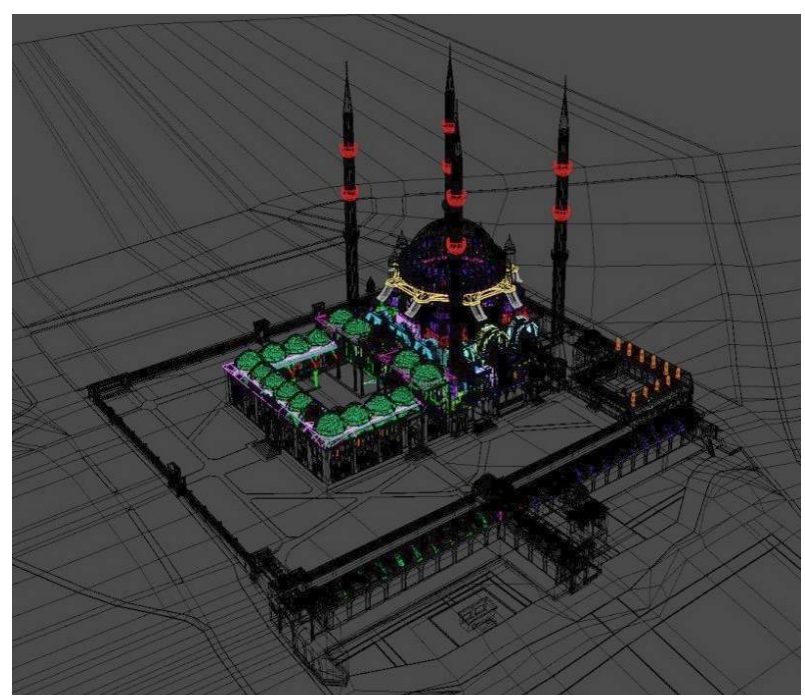

Fig. 10. Coloured object parts of the mosque indicate all objects with polygons reduced 


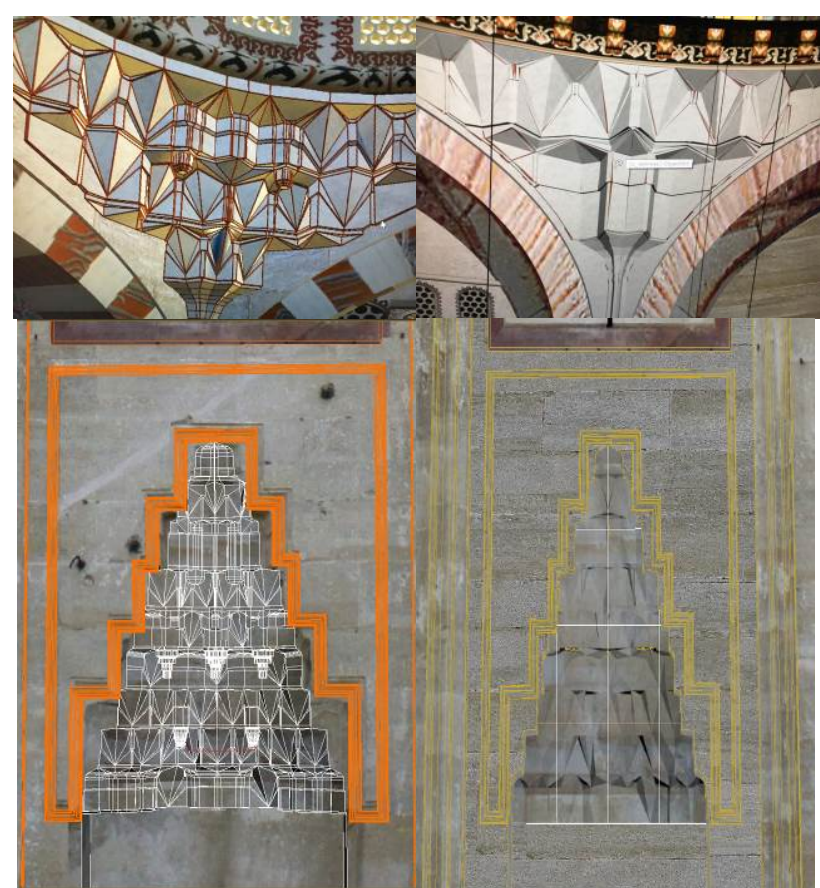

Fig. 11. Two examples for polygon reduction - original data before (left) and new data for the game engine after reduction (right)

\section{THE VR IMPLEMENTATION}

For a virtual walk within a real environment, the dimensions of the object must be to scale. The basis for the VR visualisation was therefore the textured CAD model generated in $3 \mathrm{ds}$ Max. After data import into the Unity engine some material parameters had to be adjusted because even after many years of game design the transformation of $3 \mathrm{D}$ models into game engines is still a task to be solved completely. Locomotion in VR is currently also an area of active research. McCaffrey (2017) gives an overview of various locomotion methods and their implementation in the game engine Unreal. Most experiences implemented on the hardware, described in section 7 , use natural locomotion where real walking movements are translated to virtual movements and the limitation of the tracked physical space is extended by teleportation. Due to the immense height of the mosque's interior and exterior, an artificial locomotion scheme was utilized that is not limited to the ground plane. By pointing the motion controllers, the direction of a flightpath is selected and the user is continuously moved while pressing a trigger style controller button. The velocity of the movement can be adjusted using the Vive touchpad where the information is also displayed in form of a small UI (Fig 12). The movement feature was implemented using the SteamVR package from the Unity asset store.

Virtual reality utilizing a HMD is a solitary task by definition, because all outside senses are dampened to enhance the immersion and, therefore, the experience. To create a more social experience, multiple users can join the experience to explore the virtual object together as avatars while each user is at a different real world location using a HMD (Fig 13). The independent networking solution Photon (Photon Unity Networking) is used to implement the synchronisation of multiuser movements. Voice is acquired through the included microphone in the HMD and played back for all users with respect to the speaker's position (spatialized audio). Photon also provides the server infrastructure and is free to use for a moderate user count.

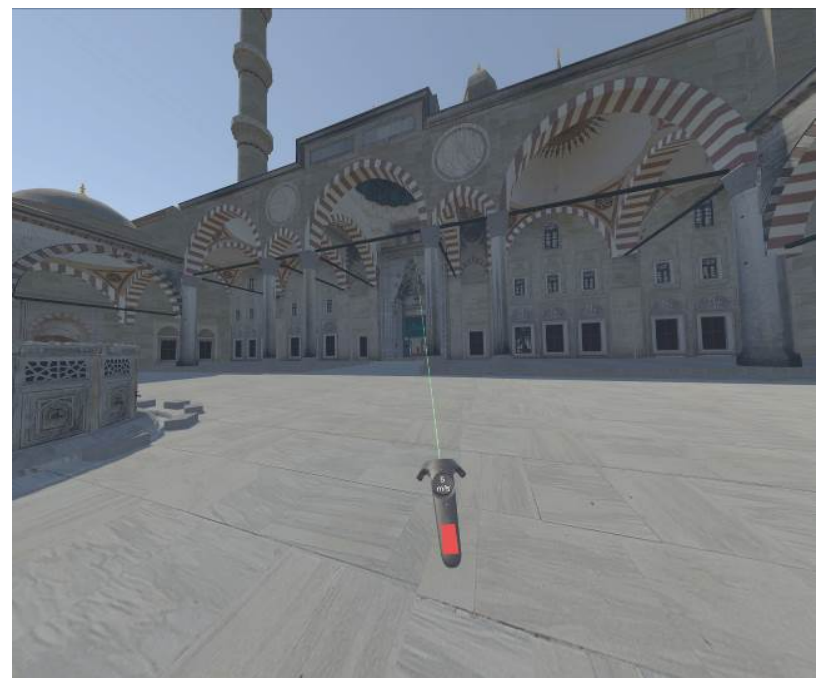

Fig. 12. The Virtual Reality System HTC Vive in action using navigation controller for the motion in the environment

The multi-user functionality was tested between Hamburg and Istanbul on February $14^{\text {th }} 2017$, when four users simultaneously visited the virtual model of the mosque to discuss and to check the geometric quality of the modelled $3 \mathrm{D}$ data during the VR visualisation. During the joint virtual visit, the users communicated with each other about the content via microphone. At the groups of users were based at two different locations, Hamburg and Istanbul, travel expenses could be avoided.

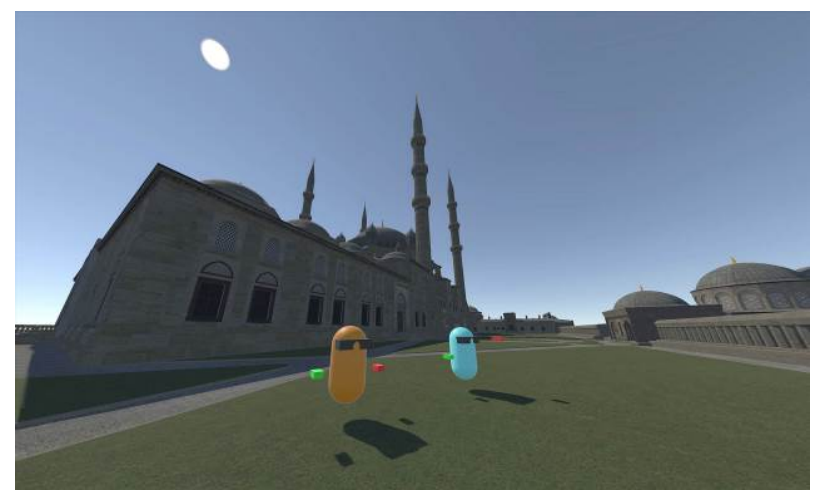

Fig. 13. Multi-user feature of the Virtual Reality System HTC Vive presenting two avatars with controllers

\section{CONCLUSION AND OUTLOOK}

In this contribution, the digital workflow from data acquisition to the immersive visualisation of the Selimiye mosque of Edirne has been presented. Based on the modelled and textured 3D data in the game engine, an immersive virtual reality visit was developed utilizing the new Virtual Reality System HTC Vive. This VR system provides a truly immersive experience that allows the users to step inside a virtual building environment, such as the mosque, without having ever seen the building in real life. The multi-user functionality offers new capabilities for interested parties to hold interactive discussions about aspects such as the architecture, structural analysis, building history and virtual restoration of a monument or a building. Moreover, the 
VR application enables geometric quality checking of the modelled 3D data during the VR visualisation.

However, comprehensive and time-consuming data recording, modelling and texture mapping of the real environment is an essential requirement for the creation of an immersive visualisation in virtual reality. In addition to this, a smooth visualisation can only be guaranteed if the data volume, i.e. the number of polygons and texture resolution, of the environment to be visualised has been reduced and adapted respective to the available computer performance. It does not matter whether the monument or the building is a reconstruction of something previously destroyed and forgotten, such as the castle of Bad Segeberg, Germany (Deggim et al. 2017), or if the object is a surviving monument, such as the imperial cathedral of Königslutter, Germany (Kersten et al. 2012) or many others. Cultural heritage monuments are ideal objects for immersive virtual reality visualisation for applications in architecture, building information modelling and restoration.

Virtual reality is an entirely new medium whose true purpose is slowly being realized. CNET (2017) describes everything the users need to know about what VR is and how it will affect our life in the near future by the following applications: entertainment, artistry \& design, gaming, education \& simulation (e.g. in medicine, chemistry, physics, astronomy), tourism \& exploration, psychology \& meditation, real estate \& shopping, and social \& telepresence.

Furthermore, the emerging technology Augmented Reality also offers great potential by combining the advantages of a virtual with a real visit to a monument. It also enables an in situ monument visit using a Smartphone or tablet for digital superimposition of a historic building state onto the current reality, for example at sites of (former) historic ground (Canciani et al. 2016).

\section{REFERENCES}

Anderson, E. F., McLoughlin, L., Liarokapis, F., Peters, C., Petridis, P. \& De Freitas, S., 2010. Developing Serious Games for Cultural Heritage: a State-of-the-art Review. Virtual reality, 14(4), 255-275.

Blair, S. \& Bloom, J. M., 1995. The art and architecture of Islam 1250-1800 (Vol. 46). Yale University Press.

Canciani, M., Conigliaro, E., Del Grasso, M., Papalini, P. \& Sacconea, M., 2016. 3D Survey and Augmented Reality for Cultural Heritage. The Case Study of Aurelian Wall at Castra Praetoria in Rome. ISPRS-International Archives of the Photogrammetry, Remote Sensing and Spatial Information Sciences, 41 (B5), 931-937.

Cochrane, N., 1994. VFX-1 Virtual Reality Helmet by Forte. Game Bytes Magazine, http://www.ibiblio.org/GameBytes/issue21/flooks/vfx1.html.

CNET, 2017. Virtual Reality 101. https://www.cnet.com/special-reports/vr101/, last access 27 March 2017.

Desai, P. R., Desai, P. N., Ajmera, K. D., \& Mehta, K., 2014. A Review Paper on Oculus Rift - a Virtual Reality Headset. International Journal of Engineering Trends and Technology (IJETT), 13(4), 175-179.
Deggim, S., Kersten, T., Lindstaedt, M., Hinrichsen, N., 2017. The Return of the Siegesburg - 3D-Reconstruction of a Disappeared and Forgotten Monument. The International Archives of the Photogrammetry, Remote Sensing and Spatial Information Sciences, XLII-2/W3, 3D Virtual Reconstruction and Visualization of Complex Architectures, 1-3 March 2017, Nafplio, Greece, Editor(s): D. Aguilera, A. Georgopoulos, T. Kersten, F. Remondino, and E. Stathopoulou, 209-215.

Dursun, S., Sagir, D., Büyüksalih, G., Buhur, S., Kersten, Th., Jacobsen, K., 2008. 3D City Modelling of Istanbul Historic Peninsula by Combination of Aerial Images and Terrestrial Laser Scanning Data. $4^{\text {th }}$ EARSel Workshop on Remote Sensing for Developing Countries/GISDECO 8, Istanbul, Turkey, June 4-7, 2008

Gaitatzes, A., Christopoulos, D. \& Roussou, M., 2001. Reviving the Past: Cultural Heritage meets Virtual Reality. Proceedings of the Conference on Virtual Reality, Archaeology and Cultural Heritage, 103-110.

HTC Corporation, 2017. Recommended Computer Specs. https://www.vive.com/us/ready/, last access 27 March 2017.

Kersten, Th., Büyüksalih, G., Baz, I., Jacobsen, K., 2009. Documentation of Istanbul Historic Peninsula by Kinematic Terrestrial Laser Scanning. The Photogrammetric Record, 24(126): 122-138

Kersten, T. \& Lindstaedt, M., 2012. Virtual Architectural 3D Model of the Imperial Cathedral (Kaiserdom) of Königslutter, Germany through Terrestrial Laser Scanning. EuroMed 2012 Int. Conference on Cultural Heritage, Ioannides, M.; Fritsch, D.; Leissner, J.; Davies, R.; Remondino, F.; Caffo, R. (Eds.), Lecture Notes in Computer Science (LNCS), Volume 7616, Springer-Verlag Berlin Heidelberg, 201-210.

Kersten, T., Tschirschwitz, F., Deggim, S., 2017. Development of a Virtual Museum including a 4D Presentation of Building History in Virtual Reality. The International Archives of the Photogrammetry, Remote Sensing and Spatial Information Sciences, XLII-2/W3, 3D Virtual Reconstruction and Visualization of Complex Architectures, 1-3 March 2017, Nafplio, Greece, Editor(s): D. Aguilera, A. Georgopoulos, T. Kersten, F. Remondino, and E. Stathopoulou, 361-367.

Mortara, M., Catalano, C. E., Bellotti, F., Fiucci, G., HouryPanchetti, M. \& Petridis, P., 2014. Learning cultural heritage by serious games. Journal of Cultural Heritage, 15(3), 318-325.

McCaffrey, M., 2017. Unreal Engine VR Cookbook: Developing Virtual Reality with UE4 (Game Design). $1^{\text {st }}$ Edition. Addison-Wesley.

Rheingold, H., 1991. Virtual Reality: Exploring the Brave New Technologies. Simon \& Schuster Adult Publishing Group. 